\title{
Establishment and characterization of a novel cell line derived from type $A B$ thymoma
}

\author{
Qiangling Sun ${ }^{1 \#}$, Zhitao Gu ${ }^{2 \#}$, Lei Zhu ${ }^{3}$, Xiaohua Yang ${ }^{1}$, Weigang Zhao ${ }^{2}$, Shubin Guan ${ }^{2}$, Wentao Fang ${ }^{2}$ \\ ${ }^{1}$ Central Laboratory, ${ }^{2}$ Department of Thoracic Surgery, ${ }^{3}$ Department of Pathology, Shanghai Chest Hospital, Shanghai Jiao Tong University, \\ Shanghai 200030, China \\ Contributions: (I) Conception and design: W Fang, Q Sun; (II) Administrative support: W Zhao; (III) Provision of study materials or patients: S Guan; \\ (IV) Collection and assembly of data: Z Gu, Q Sun; (V) Data analysis and interpretation: L Zhu, X Yang; (VI) Manuscript writing: All authors; (VII) \\ Final approval of manuscript: All authors. \\ "These authors contributed equally to this work. \\ Correspondence to: Wentao Fang. Department of Thoracic Surgery, Shanghai Chest Hospital, Shanghai Jiao Tong University, Shanghai 200030, \\ China. Email: vwtfang12@shchest.org.
}

Background: Thymoma has been recognized as the most prevalent tumor of anterior mediastinum. Nevertheless, due to the diverse classification of its subtypes and the absence of proper pre-clinical models, the therapeutic progress of thymoma has been hampered. Therefore, the present study reported the establishment and characterization of a novel human thymoma cell line, designated as T68, which may be useful for exploring the molecular and biological characteristics of thymoma.

Methods: Thymoma cell line was derived from a male type AB patient aged 44 years. Furthermore, the morphology, growth rate and ultrastructure of this cell line, together with the expression of epithelial cell markers, were studied in this work. Morphology and immunohistochemical reactivity assays were conducted for the characterization of the established xenografts.

Results: Thymoma cells grew and formed a monolayer in an adhering manner, with doubling time of 30 to 48 hrs. The ultrastructural analysis results revealed secretary vesicles and microfilaments, as well as the desmosomes and tight junctions. No reaction of the T68 cell line was observed to B-cell and T-cell lineage markers (e.g., TdT, CD5), while this cell line exhibited a more significant reaction to epithelial markers (e.g., CK8, CK18, CK19). The xenografted tumor was recognized as type AB thymoma. For the nude mice, the cell line exhibited tumorigenicity. In addition, the xenografts showed histologic characteristics that were comparable with the original tumor from which this cell line was derived.

Conclusions: The established thymoma cell line and xenograft model proposed in this study is potential to be used for further multi-aspect studies of human thymoma biology and proposal of new treatment strategies.

Keywords: Thymoma; WHO classification; type AB; primary culture

Submitted Jan 09, 2018. Accepted for publication Dec 07, 2018.

doi: $10.21037 /$ tcr.2018.12.12

View this article at: http://dx.doi.org/10.21037/tcr.2018.12.12

\section{Introduction}

Thymoma has been recognized as a common epithelial tumor in the anterior superior mediastinum. Its incidence is estimated to be 3.93 per 1,000,000 individuals in China. Malignant potential is considered for all thymic tumors now. Distant metastasis has emerged even at the early stage of type $A$ or type $A B$ thymoma. And the recurrence after complete resection of stage I disease is not rare $(1,2)$.

However, no definite results have been obtained in terms of the molecular basis of this aggressive behavior until now. Therefore, it is necessary to investigate thymoma cancer biology, which would shed some light on the 

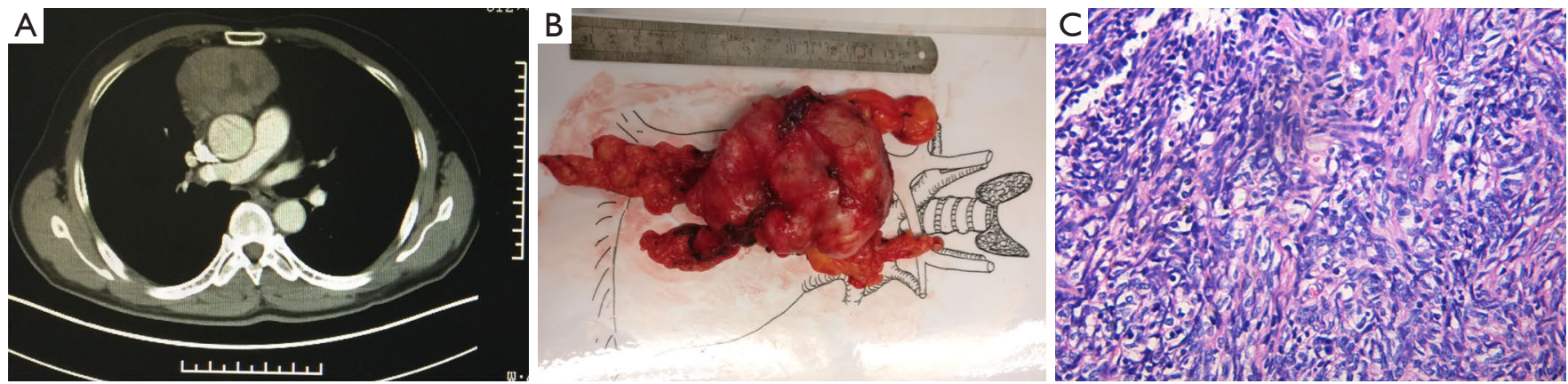

Figure 1 Patient's anterior mediastinum image and histological patterns of the primary thymic tumor. (A) Enhanced computed tomography (CT) scan image of the patient; (B) overview of the primary thymic tumor; (C) hematoxylin and eosin (H\&E) staining of the biopsied specimen diagnosed as type $\mathrm{AB}$ thymoma $(\times 200)$.

development of prevention and treatment strategies $(3,4)$. Cell lines can infinitely supply a relatively homogeneous and self-replicable cell population, thus recognized as a vital experimental tool in the researches of various kinds of cancer. It is noted that comparative studies can be facilitated due to the wide distribution of the cell population. To conduct the cellular and molecular studies for malignant diseases and propose new biological therapeutic targets, cell cultures have been directly established from human tumors. However, basic research remained stagnant due to the lack of appropriate cell lines and animal models. It has been reported that few thymoma cell lines have been successfully established from primary tumors, but generally speaking, the previous studies are far from enough and still unable to meet the needs for more and more current basic researches about thymoma (5-9).

This work proposed a novel human thymoma cell line (T68) and its biomolecular features were investigated. In addition, the morphology, ultrastructure and growth features of this cell line were described, as well as the expression of epithelial cell markers. Furthermore, morphology and immunohistochemical reactivity studies were performed for the characterization of the xenografts established herein. The thymoma cell line establishment is of vital importance for the exploration of new therapeutic modalities.

\section{Methods}

\section{Clinical patient bistory}

A 44-year-old man with slight dyspnea was referred to our hospital. The CT images (Figure 1) revealed a tumor of
$11 \mathrm{~cm} \times 10 \mathrm{~cm} \times 6 \mathrm{~cm}$ in the right thoracic cavity. The tumor had some adhesion to the mediastinal pleura and the right lung. Extended thymectomy and wedge resection of the right upper lobe were therefore performed through median sternotomy. The excised specimen showed a tumor of $10.5 \mathrm{~cm} \times 10 \mathrm{~cm} \times 6 \mathrm{~cm}$ and the weight of the tumor was $385 \mathrm{~g}$ (Figure 1). After pathological examination, the tumor was recognized as type $\mathrm{AB}$ thymoma according to the World Health Organization classification and MasaokaKoga stage I (Figure 1). The immunohistochemistry results provided by our pathologists showed the positive expression of CK, CK19, CK5/6 and negative expression of EMA, CD20, CD1a, KP1 in epithelial cells. CD3, CD5 and TDT were only detected in lymphocytes. Postoperative patients recovered well and no relapse was found in the 4-year follow-up.

This study was approved by the ethical committee of the Medical Council of Shanghai Chest Hospital. The informed consent was signed by this patient, and the protocol of this study was approved by the ethics committee of the Faculty of Shanghai Chest Hospital.

\section{Primary culture and morphological analysis}

In brief, the sterile tumor sample from this patient was rinsed with $0.9 \%$ normal saline, and small fragments of tissue were obtained by mincing the specimens with scissors. The culture medium was prepared by adding FBS (5\%), penicillin (1\%) and streptomycin into the RPMI-1640 medium (Gibco ${ }^{\circledR}$, Life Technologies ${ }^{\mathrm{TM}}$, USA). The prepared medium was replaced every 4 days. The tissue culture was performed in a humidified atmosphere with $95 \%$ air and 
$5 \% \mathrm{CO}_{2}$ at $37{ }^{\circ} \mathrm{C}$. EDTA free trypsin was used to protect the vulnerable primary cells. Tissues were first cultured in 12 -well culture dishes. After 4 weeks, when it reached $80 \%$ confluency, the cells were transferred into 6-well dishes, then to $10 \mathrm{~cm}$ dishes in the following passages.

At these culturing passages, cells were stored in liquid nitrogen in the culture medium supplemented with FBS (20\%) and DMSO (10\%). The adherent cells were maintained for more than two years in the culture medium and underwent 100 passages.

The ultrastructure was also investigated in this study. In brief, the established cell lines on dishes $(3.5 \mathrm{~cm})$ were rinsed using PBS for 3 times, followed by fixation using glutaraldehyde $(2.5 \%)$ and paraformaldehyde $(2 \%)$ in $\mathrm{pH}$ 7.4 phosphate buffer $(50 \mathrm{mM})$. Afterwards, post-fixation was conducted in $\mathrm{OSO}_{4}(1 \%)$. After dehydration in graded ethanol, these specimens were embedded in epoxy resin. Then these specimens were cut into 400-500 $\mu \mathrm{m}$ ultrathin sections. Finally, these sections were stained using lead citrate and uranyl acetate before transmission microscope observation.

\section{Growth features}

The cells in the growth medium were seeded $\left(1 \times 10^{5}\right.$ cells $\left./ 5 \mathrm{~mL}\right)$ to culture dishes $(60 \mathrm{~mm})$. The dishes were collected in triplicate, and counted every day. The trypan blue exclusion method was used for the determination of cell viability throughout the test. At the exponential growth stage, the doubling time was determined.

\section{Immunocytochemistry (ICC) of the phenotype of the thymoma cell line and immunobistochemistry (IHC) of the xenograft}

Comparative study was conducted between the in vivo grown tumors and in vitro grown cells by seeding these established cell lines to autoclaved glass slides in 24-well plates. Then these cells grew on the aforementioned glass slides. This was followed by immediate cell fixation in acetone (100\%; ice-cold) in the culture plates.

To prepare the specimens of xenograft tumor tissues, primary tumors were excised after sacrificing the test animals. These tumors were fixed in buffered formaldehyde (4\%) for $24 \mathrm{~h}$, followed by phosphate buffer rinsing. After dehydration in a series of graded ethanol, these tumor specimens were embedded in paraffin. The prepared tumor specimens were cut into sections (thickness: $4 \mu \mathrm{m}$ ). To study the immunohistochemistry, antigen retrieval was performed under pressure at $110^{\circ} \mathrm{C}$ using citrate buffer $(0.01 \mathrm{mmol} / \mathrm{L}$; $\mathrm{pH}$ 6.0).

$\mathrm{H}_{2} \mathrm{O}_{2}(3 \%)$ was used to inhibit the internal peroxidase activity, followed by antibody application. Based on the protocol of the manufacturer (DAB), the peroxidase method was employed during the standard indirect immunoperoxidase assays. For IHC and ICC analyses, the following antibodies were used: anti CK8 (Abcam, Cambridge, UK), anti CK18 (CST, Beverly, USA), anti EGFR, anti CK19, anti-vimentin, anti TdT, anti PanCK, anti CK5/6, anti-vimentin, anti-annexin 1, anti CD1a, anti C-kit and anti CD5 (ZSGB-BIO, Beijing, China).

\section{Thymoma xenograft models}

The thymoma xenograft model was established by subcutaneously injecting $1 \times 10^{7}$ cells into 5 -week-old nude mice from the flanks (BALB/c nu/nu, Shanghai Lab Animal Research Center). The sizes of tumors were measured using calipers. The formula of $\left(a \times b^{2}\right) / 2$ was used for calculation of the tumor volume. In this formula, "a" and "b" referred to the longest diameter and the shortest diameter of the tumor, respectively. To study the histomorphological characteristics, hematoxylin and eosin staining (H\&E) staining was carried out on the sectioned tumor specimens of these nude mice. And IHC was conducted to investigate a series of epithelial membrane antigens, cytokeratin markers, as well as mesenchymal markers.

\section{Statistical analysis}

The analytical results are expressed as average values \pm standard deviations. The data comparison was conducted using two-tailed Student's $t$-test. $\mathrm{P}<0.05$ indicated statistical significance.

\section{Results}

\section{Establishment of the T68 cell line and morphological analysis}

From the diagnosed patients, 44 biopsies were collected and used for 31 primary cultures. However, after 20 times of passages, we only observed one good cell growth.

Based on type $\mathrm{AB}$ thymoma, the proposed thymoma cell line was separated. Tumor tissues were admixed with variable number of lymphocytes in the first 1 or 2 days. 

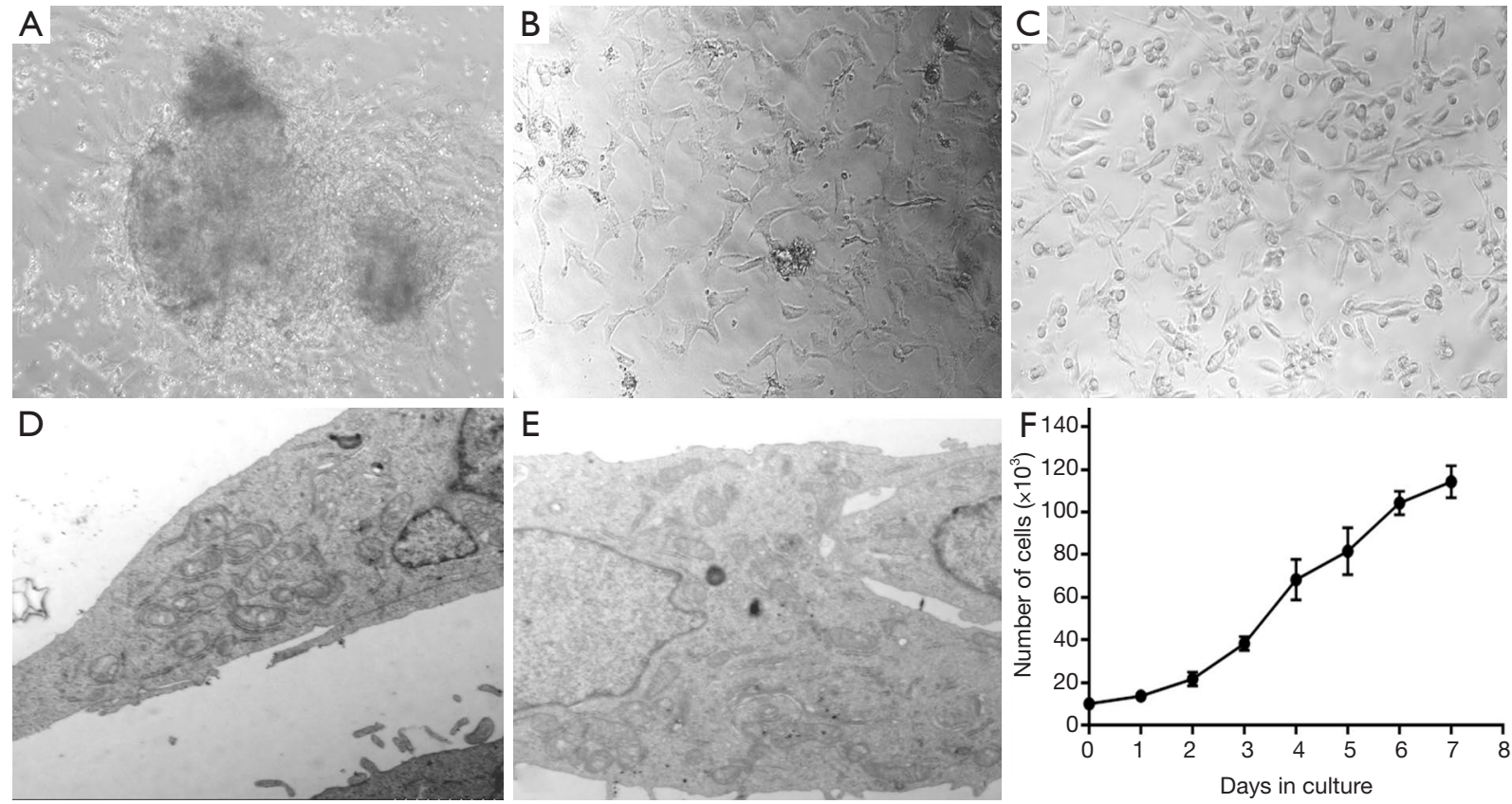

Figure 2 Morphological features and transmission electron micrographs of T68 cell line in vitro. (A,B,C) Morphology of the cell line on day 7, 20, 30, respectively. Cells grew in RPMI-1640 medium $(\times 200)$; (D,E) ultrastructure of the T68 cell line $(\times 30,000)$; (F) the growth curve of the T68 cell line.

After 7 days, initial growth of single cells from tumor tissues was observed. The adherence of cell clusters onto the cell culture plate surface was observed within the initial 2 weeks, along with the gradual formation of cell colonies. At the initial stage, proliferation of the contaminated fibroblastic cells was found, which were surrounding the aforementioned colonies of tumor cells. Differential trypsinization and low concentration FBS were used to eliminate fibroblasts. Figure 2 showed the gradual decrease of the fibroblastic cell number through serial passages, and eventually these cells were completely substituted by tumor cells. After stable growth of the cells was observed, the cells were passaged every four to five days with $10 \%$ FBS. The light microscope observation revealed tight monolayer adherence of all cells onto the culture flask bottoms. Meanwhile, the thymoma cells were polygonal and spindleshaped.

The transmission electron microscopy was carried out to study the cell ultrastructure, and the results provided further evidence for the epithelial lineage of cells. A rim of elongated encircled cytoplasm covered elongated eccentric nuclei. The nucleus, containing 2 or 3 nucleoli, was hyperchromatic. Ribosomes, along with bundles of microfilaments and secretary vesicles, were observed in the cytoplasm. Through tight junctions and desmosomes, these polygonal cells were attached onto each other. Figure 2 also showed the presence of some microvilli on the surface of cells.

Figure 2 showed the growth curve of the cells based on the growth kinetics of the T68 cell line obtained at passage 20 , with a population doubling time of $37 \mathrm{~h}$.

\section{Immunocytochemical characterization of T68 phenotype}

As shown in Figure 3, the cells treated after immunocytochemical staining were characterized via representative images. The positive immunoreactivity towards CK8 and CK18 provided evidence for the epithelial phenotype. Significantly positive expression of vimentin and annexin 1 was observed in these culture cells. For TdT, CD5 and other lymphocyte markers, these cells were found to be negative. In addition, compared with the negative control group, these cells were found to be weakly positive for the expression of EGFR or Pan-CK, and also negative for c-kit and EMA.

\section{Tumorigenicity in vivo}

Subcutaneous injection of five athymic mice (5-week-old) 

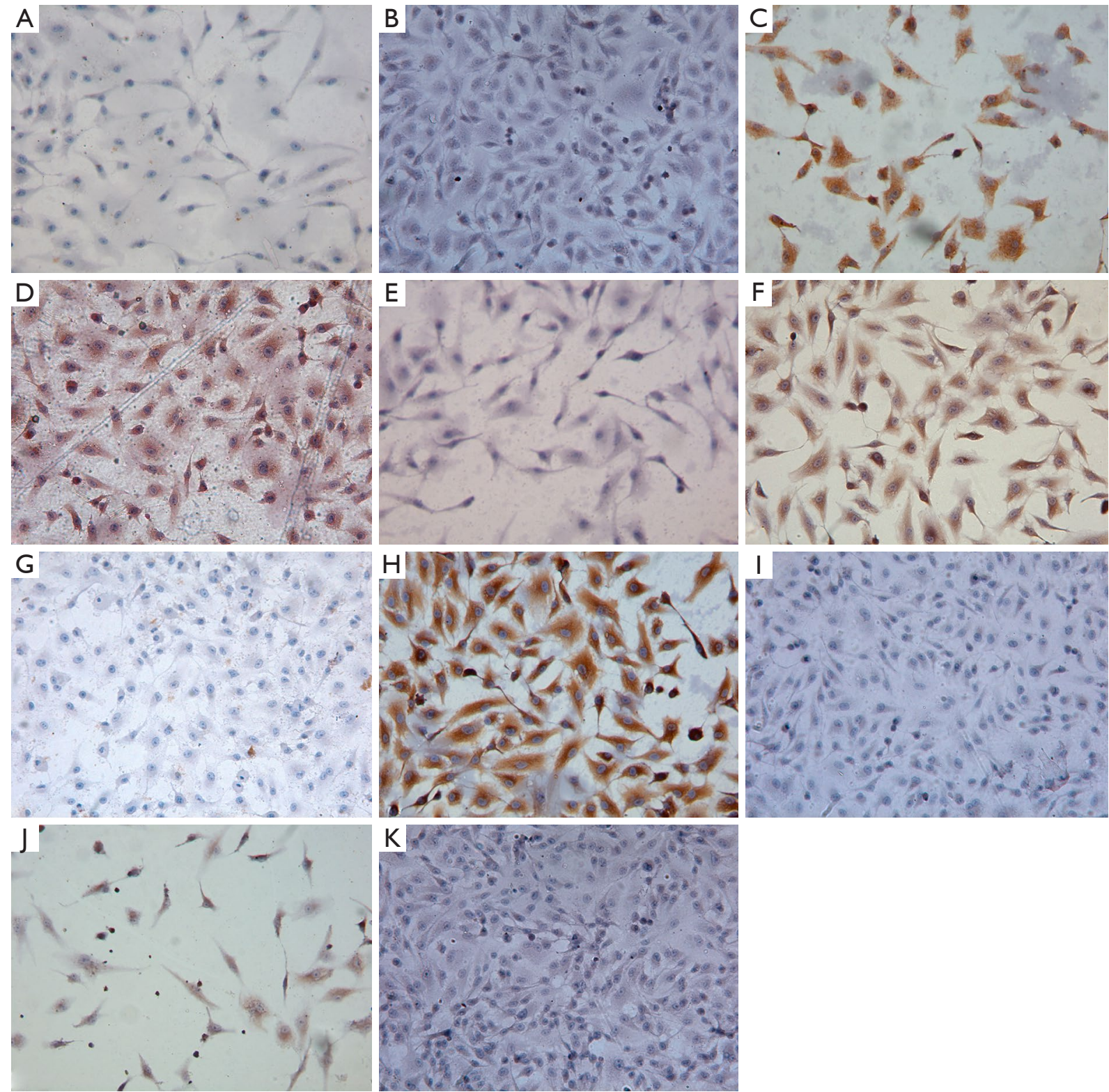

Figure 3 Immunocytochemical staining analyses of T68 cell line in vitro by using different epithelial and lymphocyte markers. (A) Negative control; (B) EGFR; (C) vimentin; (D) Annexin-1; (E) TdT; (F) CK18; (G) CD5; (H) CK8; (I) EMA; (J) Pan-CK; (K) C-kit. Magnification: ×100.

with $1 \times 10^{7}$ cells $(\mathrm{BALB} / \mathrm{c} \mathrm{nu} / \mathrm{nu})$ was performed, so as to assess the probability of T68 cells in tumor formation for immunodeficient nude mice. For all injected specimens, the tumor masses were first found at their injection sites on the $18^{\text {th }}$ day. At 4 weeks, the cells formed masses of $1 \mathrm{~cm}$ in diameter, About two months after injection, the tumors reached a volume of $1.1 \mathrm{~cm}^{3}$ (Figure 4). This indicated that T68 cells were tumorigenic.

\section{Morphology and immunohistochemistry of thymoma in vivo}

Using H\&E staining, T68 cells showed the typical type $\mathrm{AB}$ morphology in vivo, which was confirmed by two experienced pathologists. Some small cells were infiltrated in the mixture of the long spindle cells and polygonal epithelial cells (Figure 4).

Immunostaining of the cells revealed that the in vivo cells maintained strong expression of vimentin as the 

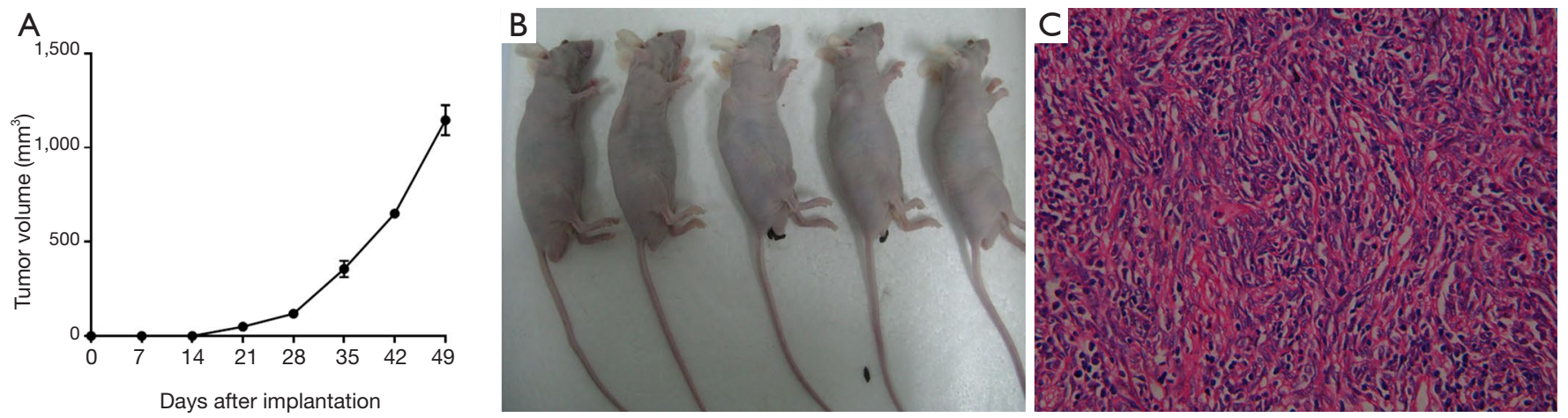

Figure 4 The in vivo properties of T68 cell line. (A) The tumor growth of nude mice after implantation of the T68 cell line; (B) Significant tumor formation in the nude mice after transplantation with T68 cells for 7 weeks; (C) a paraffin section of a xenograft formed by T68 cells was stained with $\mathrm{H} \& \mathrm{E}(\times 200)$.

in vitro culture cells. The expression of vimentin was mostly in the long spindle-shaped epithelial cells. Interestingly, the pan CK expression was much higher compared to in vitro culture. Furthermore, compared to original cells, the xenograft cells were negative for CK8, CK18 and EGFR. EMA expression was detected in few of the spindle cells compared to the original tumor. CK5/6 was weakly positive and CK19 was moderately positive. TdT and CD1a staining were negative in CK positive cells (Figure 5). All these were more congruent with the pathology report of the primary tumor of the patient.

\section{Discussion}

The present work proposed the separation of a certain cell line from a 44-year-old type $\mathrm{AB}$ thymoma patient without myasthenia gravis (MG). Meanwhile, the cell line's morphology, growth characteristics, epithelial markers and tumorigenicity were explored.

To investigate the biological features of various tumors, in vitro models are usually established, where the tumor cell lines play vital roles. However, some technical difficulties remain in establishing permanent cell cultures, together with the thymic malignancy's rare incidence, only seven cell lines have been established successfully in the past several years (5-9). In 1992, the first human thymic malignancy cell line designated Ty- 82 was established from an undifferentiated thymic carcinoma patient (5). In 2008, another thymic carcinoma cell line designated ThyL-6, which was derived from a 57 -year-old male patient, was constructed by Inai (7). Ehemann established the first human type B1 and another thymic carcinoma cell line
TC1889 in 2008 (6). Since then, Polar established the first human type AB thymoma cell line IU-TAB-1 in 2012 (8). Based on the study of patients suffering type $A B$ thymoma with MG, a new cell line was successfully established by Wang in 2015 (9). In 2016, a thymic carcinoma specimen was used to obtain a novel cell line by Alberobello (10). The established cell lines aided our understanding about pathogenesis of thymic malignancy. For example, by using TSCC cell lines, the role of miR-145-5p and its epigenetic transcriptional regulation were evaluated in vitro (11). Taking advantage of IU-TAB-1 and 1889c cell lines, BIRC3 gene knockdown induced apoptosis was found. And, the importance of $\mathrm{PI} 3 \mathrm{~K} / \mathrm{AKT} / \mathrm{mTOR}$ pathway in type $\mathrm{AB}$ thymoma was confirmed $(12,13)$. However, with the rapid development of the cell biology and molecular biology, it is essential to construct more and more human thymoma cell lines to meet the current requirement.

In our work, the tissue explants adherent method was employed instead of collagenase digestion. The characteristics of its morphology, ultrastructure, growth rate and expression of epithelial cell markers were investigated. The cells showed strong immunostaining for CK8, CK18 and pan CK in vitro and in vivo, separately. The cells also showed co-expression of vimentin intermediate filament in vitro, which was in accordance with Papadopoulos's report and Miki's results $(14,15)$. Histological and immunocytochemical characteristics of the cells in vitro and in vivo were concordant with those of the original tumors. It was observed that the tumor cells returned to the original histology shape of the primary tumor in vivo. And, some small cells were infiltrated in the mixture of the spindle cells and polygonal epithelial cells. CD1a and TdT were negative 

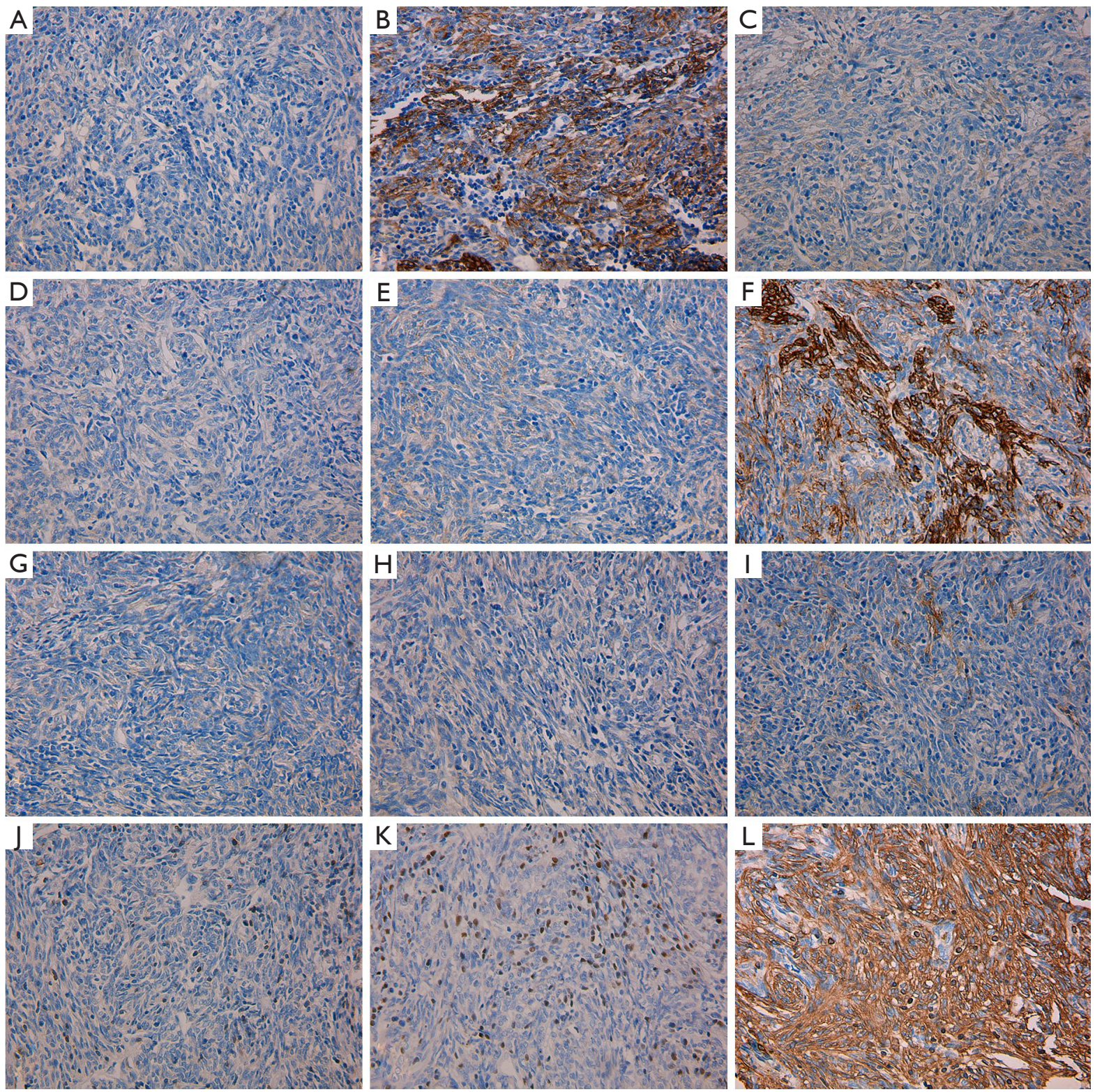

Figure 5 Immunohistochemical analysis of the thymoma cell line in vivo. (A) Negative control; (B) Pan-CK; (C) CK5; (D) CK8; (E) CK18; (F) CK19; (G) C-kit; (H) EGFR; (I) EMA; (J) CD1a; (K) TdT; (L) vimentin. Magnification: $\times 200$.

in CK positive epithelial cells. All these facts demonstrated that the thymoma cells may be induced to differentiate in vivo. So, we supposed that the T68 cell lines might be more useful for elucidating the molecular characteristics of the type $\mathrm{AB}$ thymoma, which will result in substantial contribution to thymoma translational research.

The T68 cell line has its own characteristics, when compared with the other two types of $\mathrm{AB}$ cell lines IUTAB-1 and Tyr0517 (8,9). The T68 cells resembled spindle cells, and also looked like fibroblast cells, which were slenderer than IU-TAB-1 or Tyr0517. The other two types of $\mathrm{AB}$ cells were ovoid-shaped, but a bit different in the shape. The difference might be attributed to the complexity of thymoma $\mathrm{AB}$ or the influence of the race. But there may be also other reasons for the dissimilarity between T68 and these two cells. Miki designated that there existed two distinct subtypes of the A-like components in type $\mathrm{AB}$ thymoma. In the "conventional subtype", the 
cells of the type A-like components were the same as the typical type A thymoma. On the contrary, in another "metaplastic subtype", the tumor cells of the type A-like components were identical to the fibroblast-like cells of metaplastic thymoma. In the latter subtype, the cells were negative for Pan-CK and positive for vimentin (15). All these descriptions were consistent with the T68 cell line. The T68 cell line would be the fibroblast-like cells of the metaplastic subtype AB thymoma. More importantly, this cell line seems to be undergoing epithelial-mesenchymal transition (EMT). The previous reports have proved that EMT plays a crucial role in tumor progression and metastasis. So this cell line would be more aggressive than IU-TAB-1 or Tyr0517. It was observed that in the xenograft model, the T68 cells showed stronger tumorigenicity, when compared with IU-TAB- 1 . At the $130^{\text {th }}$ day, the volume of IU-TAB- 1 was up to $1,000 \mathrm{~mm}^{3}$, while the T68 reached the same volume at around $60^{\text {th }}$ day. Moreover, compared with the Tyr0517, the supplier of T68 did not have MG.

In this study, a new cell line was successfully established from a type $\mathrm{AB}$ thymoma patient, which should provide an ideal model for investigation about the pathogenesis and new therapies for thymic malignancy. To give a more insight into the cell's characteristics, gene array and chromosome analysis would be done in the following work, and some key surface molecules would be detected according to Patel's article (16).

\section{Acknowledgments}

The authors want to sincerely thank Dr. Alexander Marx, who provided pathological expertise to characterize thymoma epithelial cell properties.

Funding: This work is supported by grants from Shanghai Municipal Natural Science Foundation (No. 17ZR1426600) and Medical Engineering Cross Fund of Shanghai Jiao Tong University (No. YG2016MS80).

\section{Footnote}

Conflicts of Interest: All authors have completed the ICMJE uniform disclosure form (available at http://dx.doi. org/10.21037/tcr.2018.12.12). The authors have no conflicts of interest to declare.

Ethical Statement: The authors are accountable for all aspects of the work in ensuring that questions related to the accuracy or integrity of any part of the work are appropriately investigated and resolved. The study was conducted in accordance with the Declaration of Helsinki (as revised in 2013). The study protocol was approved by the Ethical and Protocol Review Committee of Shanghai Chest Hospital, with the ethical approval ID number of KS1615. All procedures performed in studies were in accordance with the ethical standards of Shanghai Chest hospital. Written informed consents were obtained from all patients.

Open Access Statement: This is an Open Access article distributed in accordance with the Creative Commons Attribution-NonCommercial-NoDerivs 4.0 International License (CC BY-NC-ND 4.0), which permits the noncommercial replication and distribution of the article with the strict proviso that no changes or edits are made and the original work is properly cited (including links to both the formal publication through the relevant DOI and the license). See: https://creativecommons.org/licenses/by-nc-nd/4.0/.

\section{References}

1. Fang $\mathrm{W}, \mathrm{Fu} \mathrm{J}$, Shen $\mathrm{Y}$, et al. Management of thymic tumors-consensus based on the Chinese Alliance for Research in Thymomas Multi-institutional Retrospective Studies. J Thorac Dis 2016;8:641-5.

2. Detterbeck F, Parsons AM. Thymic tumors: a review of current diagnosis, classifcation, and treatment. In: Patterson GA, Cooper JD, Deslauriers J, et al. eds. Thoracic and Esophageal Surgery. 3rd Ed. Philadelphia: Elsevier, 2008:1589-614.

3. Girard N, Shen R, Guo T, et al. Comprehensive genomic analysis reveals clinically relevant molecular distinctions between thymic carcinomas and thymomas. Clin Cancer Res 2009;15:6790-9.

4. Giaccone G, Rajan A, Ruijter R, et al. Imatinib mesylate in patients with $\mathrm{WHO} B 3$ thymomas and thymic carcinomas. J Thorac Oncol 2009;4:1270-73.

5. Kuzume T, Kubonishi I, Takeuchi S, et al. Establishment and characterization of a thymic carcinoma cell line (Ty-82) carrying $\mathrm{t}(15 ; 19)(\mathrm{q} 15 ; \mathrm{p} 13)$ chromosome abnormality. Int J Cancer 1992;50:259-64.

6. Ehemann V, Kern MA, Breinig M, et al. Establishment, characterization and drug sensitivity testing in primary cultures of human thymoma and thymic carcinoma. Int J Cancer 2008;122:2719-25.

7. Inai K, Takagi K, Takimoto N, et al. Multiple inflammatory cytokineproductive ThyL-6 cell line established from a patient with thymic carcinoma. Cancer 
Sci 2008;99:1778-84.

8. Gökmen-Polar Y, Sanders KL, Goswami CP et al. Establishment and characterization of a novel cell line derived from human thymoma $\mathrm{AB}$ tumor. Lab Invest 2012; 92:1564-73.

9. Wang G, Wang Y, Zhang P, et al. Establishment and characterization of a novel cell line derived from thymoma with myasthenia gravis patients. Thorac Cancer 2015;6:194-201.

10. Alberobello AT, Wang Y, Beerkens FJ, et al. PI3K as a Potential Therapeutic Target in Thymic Epithelial Tumors. J Thorac Oncol 2016;11:1345-56.

11. Bellissimo T, Ganci F, Gallo E,et al. Thymic Epithelial Tumors phenotype relies on miR-145-5p epigenetic regulation. Mo Cancer 2017;10;16:88.

12. Radovich M, Solzak JP, Hancock BA, et al. A large microRNA cluster on chromosome 19 is a transcriptional hallmark of WHO type $\mathrm{A}$ and $\mathrm{AB}$ thymomas. Br J Cancer

Cite this article as: Sun Q, Gu Z, Zhu L, Yang X, Zhao W, Guan S, Fang W. Establishment and characterization of a novel cell line derived from type $\mathrm{AB}$ thymoma. Transl Cancer Res 2018;7(6):1634-1642. doi: 10.21037/tcr.2018.12.12
2016;114:477-84.

13. Huang B, Belharazem D, Li L, et al. Anti-Apoptotic Signature in Thymic Squamous Cell Carcinomas Functional Relevance of Anti-Apoptotic BIRC3 Expression in the Thymic Carcinoma Cell Line 1889c. Front Oncol 2013;3:316-24.

14. Papadopoulos T, Kirchner T, Marx A, et al. Primary cultures of human thymic epithelial tumors. Morphological and immunocytochemical characterization. Virchows Arch B Cell Pathol Incl Mol Pathol 1989;56:363-70.

15. Miki Y, Hamada K, Yoshino T, et al. Type AB thymoma is not a mixed tumor of type A and type B thymomas, but a distinct type of thymoma. Virchows Arch 2014;464:725-34.

16. Patel DD, Whichard LP, Radcliff G, et al. Characterization of human thymic epithelial cell surface antigens: phenotypic similarity of thymic epithelial cells to epidermal keratinocytes. J Clin Immunol 1995;15:80-92. 